\title{
Correlating Slump, Slump Flow, Vebe and Flow Tests to Rheological Parameters of High-Performance Concrete
}

\author{
Aminul Islam Laskar* \\ Civil Engineering Department, National Institute of Technology, \\ Silchar - 788010, India
}

Received: September 4, 2008; Revised: February 16, 2009

\begin{abstract}
Conventional single-point workability tests continue to be used for specification and quality control of concrete despite their inherent limitations. These tests cannot characterize workability of concrete in terms of fundamental rheological parameters. Attempt has therefore been made to correlate slump, slump flow, slump flow time, percent flow and Vebe time to rheological parameters of high-performance concrete. Thirty numbers of concrete mixes without steel fibers and with steel fibers of specific dose have been considered during experiment. It has been observed that rheological parameters can be correlated to slump and slump flow. In case of fiber reinforced concrete, there is a decrease in percent flow with the increase in rheological parameters. Vebe time, however, remains unchanged up to yield stress $500 \mathrm{~Pa}$ and plastic viscosity $40 \mathrm{~Pa}$.s beyond which it steeply increases with further increase in yield stress and plastic viscosity. Flow test may be a better test for FRC as it is sensitive over all ranges of workability of concrete.
\end{abstract}

Keywords: rheology, slump, slump flow, vebe time, flow

\section{Introduction}

Conventional workability test methods are no longer considered to be capable of characterizing the workability of concrete adequately. Majority of the test methods are empirical in nature and they attempt to simulate a certain field placement condition and measure the distance or time that serves as an index of workability. Researchers treat fresh concrete as a fluid and use fluid rheology method to describe concrete behavior. It is now well established that concrete as a fluid behaves like a Bingham fluid where flow is represented by yield stress and plastic viscosity ${ }^{1,2}$. Nevertheless, conventional workability test methods adopted by various standards across the world are cheap, convenient and are most commonly used to describe the workability and for quality control during concrete production and supply.

Slump test is the most widely accepted test used by the site engineers. The concrete industry has changed significantly over last century, but the slump test has remained unchanged due to its simplicity. Rheometers in general, are popular inside the laboratory. With the obvious benefits of the slump test at jobsite and with the obvious benefit of rheometers at laboratory, it is clearly important to relate the two devices. Morinaga ${ }^{3}$ found an inverse relationship between slump and yield stress determined by concentric cylinder rheometer. Murata ${ }^{4}$ confirmed the results of Morinaga using normal and lightweight concrete and suggested that slump is not influenced by plastic viscosity. Christensen ${ }^{5}$ corrected integration error in original Murata's model and converted the units to dimensional quantities. Pashias et al. ${ }^{6}$ adopted dimensionless slump model for cylindrical geometries and found excellent agreement between predicted and measured yield stress and plastic viscosity. Tanigawa and Mori ${ }^{7}$, Tanigawa, Mori and Watanbe ${ }^{8}$ performed measurements of slump as a function of time and found that both yield stress and plastic viscosity could be related to slump-time curve. Murata and Kikukawa ${ }^{9}$ experimented with automated setup and developed equation for yield value based on slump. Chidiac ${ }^{10}$ modeled yield stress and plastic viscosity in terms of slump and slump flow. Ferraris and de Larrard ${ }^{11}$ developed a modified slump cone and observed that slump and slump time could be correlated to yield stress and plastic viscosity. Saak et al. ${ }^{12}$ proposed dimensional slump model and found that a fundamental relationship exists between yield stress and slump that is independent of cone geometry. Wallevick ${ }^{13}$ demonstrated that there exists a good relationship between slump and yield stress; however, it was concluded that the relationship between plastic viscosity and slump is poor.

It is well known that the addition of any type of fibers to plain concrete reduces the workability. Steel fiber reinforced concrete (SFRC) appears stiffer compared with conventional concrete without fibers even when the workability judged by any test using vibration is same ${ }^{14}$. Since fibers impart considerable stability to a fresh concrete mass, the slump cone is not considered as a good index of workability. Vebe test is considered more appropriate for evaluating the workability of fiber reinforced concrete ${ }^{15}$. Flow test has become more popular in recent years as it is appropriate for concrete of high and very high workability, including flowing concrete which would exhibit a collapse slump ${ }^{16}$.

The objective of this paper is to investigate the relationship between slump, slump flow, slump flow time with rheological parameters of high performance concrete (HPC). The correlation between rheological parameters and Vebe time, percent flow of steel fiber reinforced concrete has also been investigated.

\section{Materials and Mix Proportions}

The cement used throughout the experiment was Ordinary Portland Cement (OPC). The properties of cement determined as per IS: 12269-1987 17 are as follows:

Specific gravity $=3.10$;

Standard consistency $=29 \%$;

Initial setting time $=65$ minutes;

Final setting time $=6$ hours;

28 day compressive strength $=50.2 \mathrm{~N} / \mathrm{mm}^{2}$. 
Locally available alluvial sand (medium; specific gravity $=2.6$ ) inside the laboratory was used throughout the experimental investigation. The particle size distribution of sand is shown in Table 1.

Crushed stone aggregates (specific gravity $=2.6$ ) of nominal maximum size $16 \mathrm{~mm}$ were used as coarse aggregate. The physical properties of aggregates were determined as per IS: 2386-1963 ${ }^{18}$. Particle size distribution is presented in Table 2.

Ordinary tap water was used for all the mixes to prepare fresh concrete. Poly-Carboxylic Polymer (PC) with set retarding effect was used as high range water reducing admixtures (HRWRA).

The mix proportions used in the present study to correlate slump, slump flow and slump flow time with rheological parameters has been presented in Table 3. To investigate the relationship between Vebe time and flow test with the rheological parameters, round steel fibers of diameters $0.50 \mathrm{~mm}$ diameter and length $50 \mathrm{~mm}$ at the rate of $1.5 \%$ by weight were added in all the mixtures in Table 3 . The specific gravity, average tensile strength and ultimate elongation of steel fibers were 7.84, 1.2 GPa and 2.5\% respectively. Mixture proportions in Table 3 were adjusted accordingly for fiber reinforced concrete.

\section{Mixing}

Concrete was mixed in a tilting mixer (laboratory type). The following mixing sequence was adopted:

- Mix coarse aggregate, fine aggregate cement (and fibers) for two minutes;

- Add water during mixing and mix for two minutes more;

- Stop mixing for one minute;

- Add HRWRA to the mix and mix for three minutes;

- Pour the concrete mix.

\section{Test Methods}

Brief descriptions of the tests conducted are given in this section. It may be noted that slump test and slump flow test have been conducted for concrete mixes without steel fibers whereas Vebe and Flow test were conducted for mixes containing round steel fibers with addition of one type of fiber at specified doze. Corresponding mixes were also subjected to rheological tests to find yield stress and plastic viscosity.

Table 1. Sieve analysis of sand.

\begin{tabular}{cc}
\hline Sieve size $(\mathrm{mm})$ & Passing $(\%)$ \\
\hline 4.75 & 98.2 \\
2.36 & 96.5 \\
1.70 & 94.6 \\
1.18 & 91.2 \\
0.60 & 66.3 \\
0.30 & 20.3 \\
0.15 & 1.6 \\
\hline
\end{tabular}

Table 2. Sieve analysis of coarse aggregate.

\begin{tabular}{cc}
\hline Sieve size $(\mathrm{mm})$ & Passing $(\%)$ \\
\hline 16 & 100 \\
12.5 & 42.20 \\
10 & 31.80 \\
6.3 & 25.0 \\
4.75 & 0.9 \\
\hline
\end{tabular}

\subsection{Slump test}

The apparatus consist of a mould in the shape of a truncated metal cone, open at both ends. The internal diameter of the slump cone is $200 \mathrm{~mm}$ at the base, $100 \mathrm{~mm}$ diameter at the top and has a height of $300 \mathrm{~mm}$. This device is usually provided with foot pieces and handles. Basically the procedure consists of filling the metal cone with concrete in three layers and each layer is compacted 25 times by a $16 \mathrm{~mm}$ rod. Thereafter, the metal cone is lifted, leaving the concrete sample behind, which slumps down by the action of gravity. Slump is measured from the highest point according to Indian Standard code of practice.

\subsection{Slump flow}

Slump flow test is an alternative test for highly workable mixes and has been incorporated in Japanese Standard: JSCE-F503 ${ }^{19}$. Slump flow is simply the measurement of the diameter of concrete after subsidence in conventional slump test. This test has the advantage that

Table 3. Mix proportions (quantities in $\mathrm{kg} \cdot \mathrm{m}^{-3}$ ).

\begin{tabular}{|c|c|c|c|c|c|}
\hline Cement & Sand & $\begin{array}{c}\text { Coarse } \\
\text { aggregate }\end{array}$ & HRWRA & Water & Remarks \\
\hline 503 & 660 & 1040 & 7.7 & 183 & - \\
\hline 558 & 444 & 1085 & 7.9 & 192 & - \\
\hline 532 & 516 & 1033 & 8.1 & 193 & - \\
\hline 505 & 491 & 1114 & 11.9 & 176 & - \\
\hline 423 & 677 & 1028 & 8.3 & 173 & - \\
\hline 300 & 647 & 1020 & 7.6 & 182 & - \\
\hline 343 & 637 & 1004 & 7.4 & 180 & - \\
\hline 385 & 627 & 988 & 7.3 & 177 & - \\
\hline 427 & 618 & 973 & 7.2 & 174 & - \\
\hline 466 & 610 & 960 & 7.0 & 171 & - \\
\hline 505 & 672 & 932 & 7.1 & 186 & - \\
\hline 588 & 590 & 930 & 8.8 & 202 & - \\
\hline 503 & 660 & 1040 & 2.78 & 209.8 & - \\
\hline 503 & 660 & 1040 & 13.9 & 198.7 & - \\
\hline 503 & 660 & 1040 & 7.7 & 183 & Coarse sand \\
\hline 503 & 660 & 1040 & 7.7 & 183 & Fine sand \\
\hline 503 & 660 & 1040 & 7.7 & 183 & $\begin{array}{l}\text { CA passing } \\
12.5 \mathrm{~mm}\end{array}$ \\
\hline 503 & 660 & 1040 & 7.7 & 183 & $\begin{array}{l}\text { CA passing } \\
10 \mathrm{~mm}\end{array}$ \\
\hline 503 & 660 & 1040 & 7.7 & 183 & CA:10-6.3 mm \\
\hline 503 & 660 & 1040 & 7.7 & 183 & CA: $12.5-10 \mathrm{~mm}$ \\
\hline 503 & 660 & 1040 & 7.7 & 183 & CA: $16-12.5 \mathrm{~mm}$ \\
\hline 484 & 705 & 940 & 6.8 & 178 & - \\
\hline 514 & 452 & 1105 & 7.4 & 197 & - \\
\hline 471 & 460 & 1125 & 7.5 & 200 & - \\
\hline 600 & 440 & 1075 & 7.2 & 191 & - \\
\hline 570 & 453 & 1107 & 7.3 & 178 & - \\
\hline 563 & 448 & 1095 & 7.2 & 185 & - \\
\hline 560 & 536 & 996 & 7.2 & 183 & - \\
\hline 555 & 660 & 909 & 7.0 & 173 & - \\
\hline 518 & 535 & 1070 & 7.1 & 186 & - \\
\hline 485 & 505 & 1140 & 7.1 & 175 & - \\
\hline
\end{tabular}

(CA means coarse aggregate). 
when testing a concrete whose workability is such that it is difficult to determine in advance if the concrete will flow, the value of either slump or slump flow as appropriate can be recorded.

\subsection{Vebe test}

Vebe is a good laboratory test that has the advantage that the treatment of concrete during the test is comparatively closely related to the method of placing in practice ${ }^{16}$. A standard slump cone is placed in a cylinder $305 \mathrm{~mm}$ in diameter, the cylinder being mounted rigidly on a flow table, adjusted to give a drop. The slump cone is filled in a standard manner, removed, and a disc-shaped rider is placed on the top of the concrete. The remolding is assumed complete when the glass plate rider is completely covered with concrete and all cavities in the surface of concrete have disappeared. It is assumed that input of energy required for compaction is a measure of workability of the mix, and this is expressed as the time in seconds, called Vebe time required for the remolding to be complete.

\subsection{Flow test}

Flow test has become more widely used in recent years as it is appropriate for concrete of high and very high workability including flowing concrete which would exhibit a collapse slump ${ }^{16}$. The apparatus consists of flow table over which concentric circles are marked. A standard mould made from smooth metal casting in the form of a frustum of a cone is kept on the centre of the table, firmly held and is filled in two equal layers, by compacting with a $16 \mathrm{~mm}$ rod. Each layer is compacted 25 times as in slump test. After lifting the mould, the table is jolted 15 times and the average diameter of the spread is noted. Flow of concrete is reported as the percentage increase in average diameter of the spread over the base diameter of the cone (250 $\mathrm{mm}$ in this case). Slump test, Vebe test and Flow test are all covered in Indian standard code of practice IS: 7320-1974 ${ }^{20}$. However, slump flow test is not yet incorporated in Indian standard code of practice.

\subsection{Rheological test}

The rheological measurements were performed with a parallel plate rheometer. The schematic diagram is shown in Figure 1. It consists of a $150 \mathrm{~mm}$ diameter vane plate driven by an AC single-phase induction motor through a gearbox. Vane plate is mounted coaxially with a cylindrical container (effective diameter $=270 \mathrm{~mm}$ ) with sleeve and bearing arrangement to ensure accurate alignment. The cylindrical container is provided with vertical ribs of $20 \mathrm{~mm}$ projection at a pitch of $60 \mathrm{~mm}$ along the circumference. Ribs are also welded at the

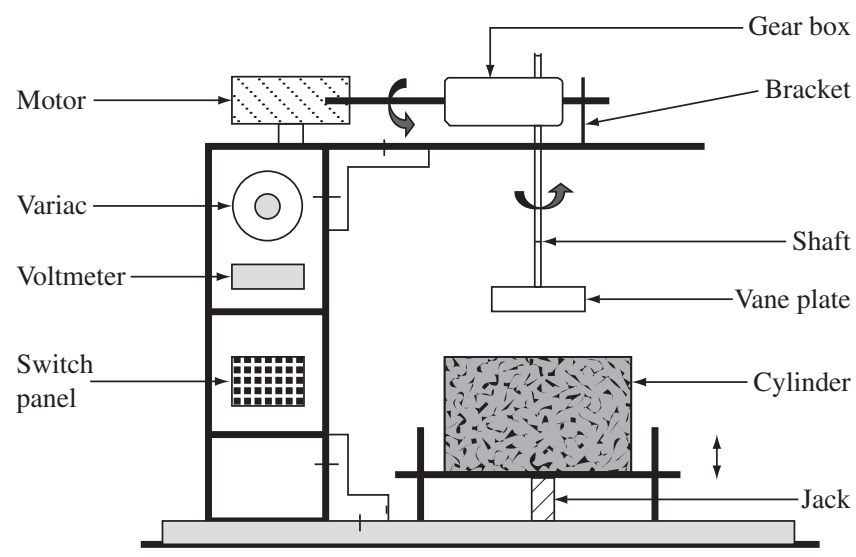

Figure 1. Schematic diagram of present rheometer bottom of the cylinder. The effective gap between the bottom and the shearing surface is $75 \mathrm{~mm}$. The effective concrete height above the vane plate is also $75 \mathrm{~mm}$. The no-slip condition at top of the cylinder is achieved by providing $20 \mathrm{~mm}$ high mesh of blades. The torque of the motor and hence the vane plate is controlled by varying input voltage with a 10 ampere $\mathrm{AC}$ variac. The number of revolution of the vane plate is measured with a non-contact infrared digital tachometer, by focusing at the retro-reflective tape glued to the spindle. The spindle has a pulley welded to it that is used for calibration purpose. The torque provided by the rheometer was calibrated in terms of input AC voltage. A spring balance anchored to a fixed object is fitted to the pulley of the spindle. When the motor is switched on, the spring balance blocks its rotor and the spring balance reading is noted. This arrangement gives the braking torques at different voltages. The calibration chart was prepared by plotting torque against input voltage. Calibration of torque was validated by testing a magneto-rheological fluid (MRF 132DG) - www.lord.com. It was observed that the measured values of shear stresses agreed reasonably well when tested by present rheometer and HAAKE RS1 rheometer. The yield stress and plastic viscosity in the present rheometer was calculated using the torque-speed relationship given by

$$
\frac{T}{\left(\frac{\pi d^{2}}{2}\left(2 h+t+\frac{d}{3}\right)\right)}=\tau_{0}+\left(\frac{\frac{d}{2 h}+\frac{2(h+t)}{g}}{2 h+t+\frac{d}{3}} \frac{\pi N d}{120}\right) \mu
$$

where, $\mathrm{N}$ is the rotational frequency in revolution per minute (rpm),

$\mathrm{T}=$ total torque;

$\mathrm{h}=$ gap between vane plate and bottom of cylindrical container;

$\mathrm{d}=$ diameter of vane plate;

$\mathrm{t}=$ height of vane plate;

$\mathrm{g}=$ gap between vane plate and vertical wall of cylindrical container;

$\tau_{\mathrm{o}}=$ yield stress;

$\mu=$ plastic viscosity.

In the present equipment, $\mathrm{d}$ (diameter of the vane plate $)=0.270 \mathrm{~m}$; $\mathrm{h}$ (effective gap between bottom of the vane plate and the bottom of the cylinder) $=0.075 \mathrm{~m}$; $\mathrm{t}$ (height of the ribs of vane plate) $=0.025 \mathrm{~m}$ and $g$ (effective gap of the annulus) $=0.060 \mathrm{~m}$. Substituting these in equation (1), one has

$$
125.75 T=\tau_{0}+0.08 N \mu
$$

The above Equation (2) is in Bingham's form. Comparing Equation (2) with Bingham equation, total shear stress (Pa) in terms of torque (N.m) can be expressed as

$$
\tau=125.75 T
$$

The overall shear strain rate (per second) in terms of rotational frequency (rpm) can be written as

$$
\dot{\gamma}=0.08 N
$$

Both the quantities $\dot{\gamma}$ and $\tau$ can be observed during the experiment. By plotting the values of $(\dot{\gamma}, \tau)$, one has the flow curve from which $\tau_{\mathrm{o}}$ and $\mu$ can be obtained. The details of the rheometer and the derivation of the expression for torque were presented elsewhere ${ }^{21}$.

The prepared concrete was transferred to the cylinder with a trowel from the same height every time. The rheological tests of the mixtures in Table 3, with and without steel fibers were carried out exactly after 15 minutes from addition of water. The mixing sequence and the time at which the rheological test was performed were identi- 
cal for all the mixes. In the present study, stepwise increasing shear stress sequence followed by a decreasing shear stress was used and the down curve was taken to draw the flow curve. A typical flow curve has been presented in Figure 2. Rheological parameters were obtained from flow curve.

\section{Results and Discussions}

\subsection{Slump, slump flow, slump flow time and rheological parameters for HPC}

Immediately after the rheological test for each sample, concrete was transferred to the mixer. Leftover concrete in the cylindrical container was cleaned manually so that all the mortar is taken in the mixture. Concrete was mixed again for two minutes and transferred for subsequent testing. Slump test was performed after 30 minutes from the addition of water. The variation of slump with yield stress and plastic viscosity is presented in Figure 3. In Figure 3, slump is plotted against $\left(\tau_{0} / \rho g\right)$ because it was shown that by dimensional analysis that slump is governed by this quantity, where $\rho$ is the density of fresh concrete in kg.m $\mathrm{m}^{-3}$, $\mathrm{g}$ is the gravitational constant ${ }^{22}$. It may be observed that there exists a linear relationship between slump and yield stress of concrete. As yield stress increases, slump value decreases and vice versa. The following empirical relation may be obtained by least square regression:

$$
S=0.21-2.87\left(\frac{\tau_{o}}{\rho g}\right)
$$

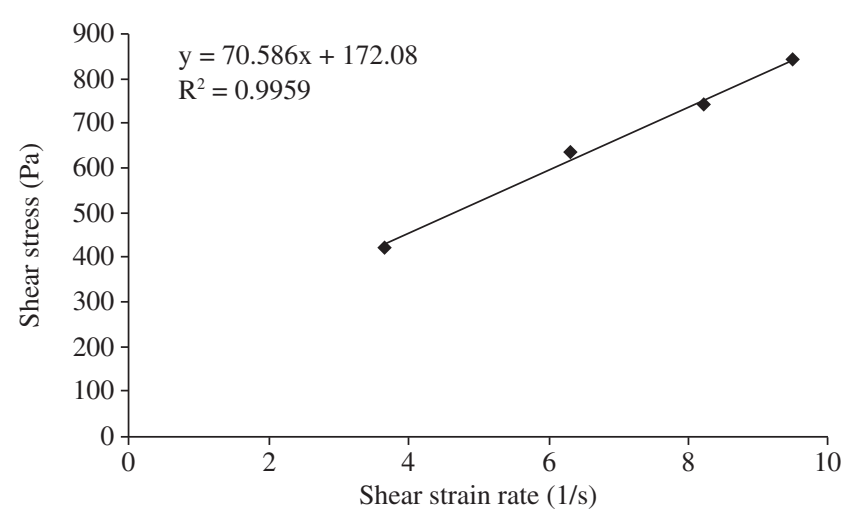

Figure 2. Typical flow curve.

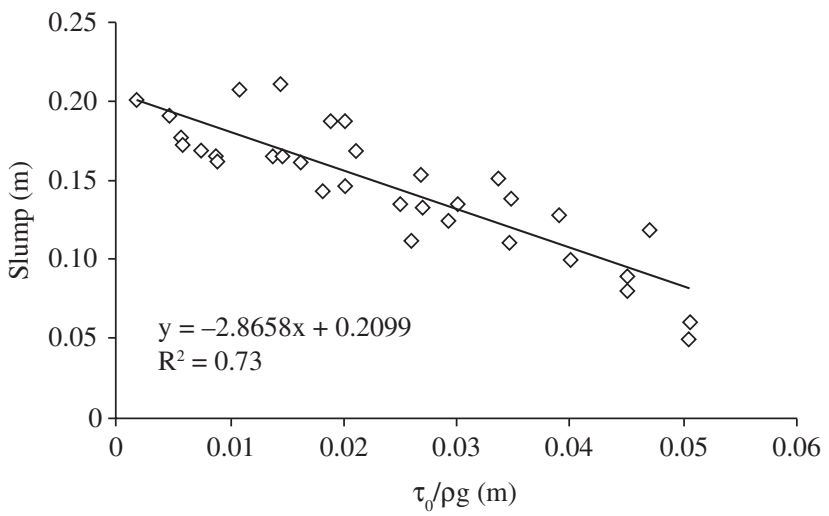

(a) where $\tau_{0}$ is $\mathrm{Pa}, \rho$ is in $\mathrm{kg} \cdot \mathrm{m}^{-3}, \mathrm{~g}$ is in $\mathrm{m}^{2} / \mathrm{s}, \mathrm{S}$ is in meter.

It may also be observed from Figure 3 that there also exists a good relationship between plastic viscosity and slump value. Initially when plastic viscosity increases, slump value also increases up to a value of 60-80 Pa.s and then decreases with further increases in plastic viscosity. Thus, there exists an optimum plastic viscosity at which slump value is the maximum. The following empirical relation may be obtained by least square regression:

$$
S=-0.048 \mu^{2}+6.63 \mu-46.1
$$

where $\mu$ is in Pa.s and $\mathrm{S}$ is in $\mathrm{mm}$.

Similar trend of yield stress versus slump was also observed by previous researchers such as Murata and Kikukawa ${ }^{9}$, Wallevick ${ }^{13}$; however, correlation between slump and plastic viscosity was observed to be poor.

In the present study, slump flow was the average of two measurements at right angles to each other after removal of cone. Slump time was the time recorded from the removal of cone up to the instant at which the flow of concrete completely stopped. This was judged visually and was recorded with a digital stop watch. The variation of slump flow with rheological properties is shown in Figure 4. It may be observed from Figure 4 that as yield stress increases, slump flow decreases linearly. For plastic viscosity, there exists an optimum value (60-80 Pa.s) beyond which any increases in it indicates a decrease in slump flow. Similarly, below the optimum value, decreases in plastic viscosity means decreases in slump flow. The following empirical relations may be derived by least square regression:

$$
\begin{aligned}
& S_{f}=655-0.238 \tau_{o} \\
& S_{f}=-0.085 \mu^{2}+12.11 \mu+161
\end{aligned}
$$

where $S_{f}$ is the slump flow in $\mathrm{mm}, \tau_{0}$ is $\mathrm{Pa}$ and $\mu$ is in Pa.s.

The relationship between slump time and rheological parameters is presented in Figure 5. From Figure 5, it may be observed that there is a good correlation between slump time and plastic viscosity. As plastic viscosity increases, slump time also increases initially. It shows a peak and then decreases gradually with further increases in plastic viscosity. The optimum range of plastic viscosity is again $60-80 \mathrm{~Pa}$.s for maximum slump time. Yield stress, however, shows no correlation with the slump time. The following empirical relation for slump flow time can be derived by least square regression:

$$
t=-0.0152 \mu^{2}+2.55 \mu-32
$$

where $t$ is in seconds and $\mu$ is in Pa.s.

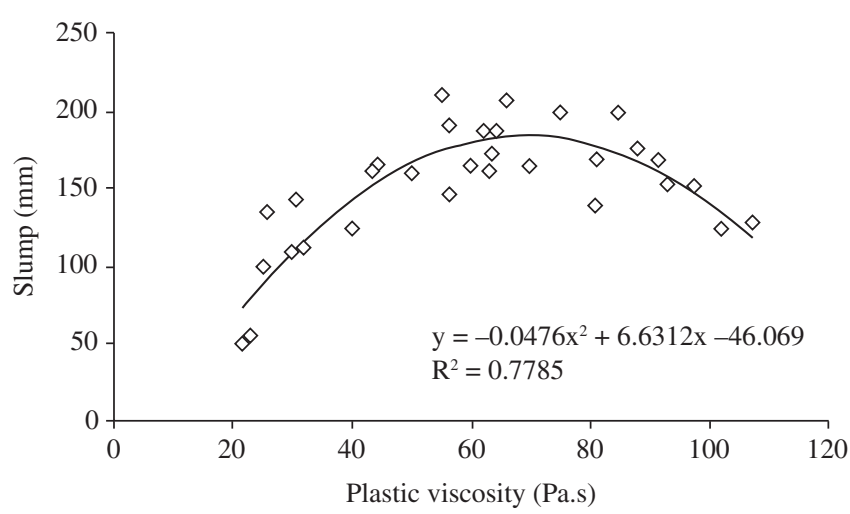

(b)

Figure 3. Variation of rheological parameters with slump a) yield stress and b) plastic viscosity. 


\subsection{Vebe time, flow test and rheological parameters for fiber reinforced concrete}

Rheological tests were carried out for concrete mixtures in Table 3 with round steel fibers. For conducting Vebe test, fresh mixtures were prepared with the same materials and mix proportions. Mixing sequence mentioned in section 3 was same for all the mixes. Vebe test was performed at the end of 15 minutes from the addition of water and the time was reckoned with a digital stop watch. The variations of yield stress and plastic viscosity with Vebe time are presented in Figure 6.

It may be observed from Figure 6 that Vebe time remains almost constant up to a value of $500 \mathrm{~Pa}$ for yield stress. Beyond this value, Vebe time increases linearly and steeply with the increase in yield stress. Vebe time also remains constant up to a value of $40 \mathrm{~Pa}$.s for plastic viscosity beyond which there is a linear increase in Vebe time with further increase in plastic viscosity. Thus it may be concluded that Vebe test is not suitable for highly workable fiber reinforced concrete having $\tau_{0} \leq 500 \mathrm{~Pa}$ and $\mu \leq 40$ Pa.s.

Flow tests were carried out for concrete mixtures in Table 3 with round steel fibers. For this purpose, fresh mixtures were prepared as in Vebe test having identical mixing sequence. Flow tests were performed at the end of 15 minutes from the addition of water. The variations of yield stress and plastic viscosity with \% flow are shown in Figure 7. It may be observed from Figure 7 that there is a very good correlation $\left(\mathrm{R}^{2}=0.9947\right)$ between yield stress and \% flow. Percent flow decreases linearly with the increase in yield stress of fiber reinforced concrete. The correlation between plastic viscosity and \% flow is also good with $\mathrm{R}^{2}=0.73$. Percent flow in this case also decreases linearly with the increase in plastic viscosity. The following empirical relations may be derived by least square regression:

$$
\begin{aligned}
& F=104.73-0.114 \tau_{o} \\
& F=109.58-1.41 \mu
\end{aligned}
$$

where $\mathrm{F}$ is the percent flow.

\section{Conclusion}

The following general conclusions may be derived from the present study:

- There is a good correlation between yield stress and slump, yield stress and sump flow. Yield stress decreases linearly as either slump or slump flow increases.

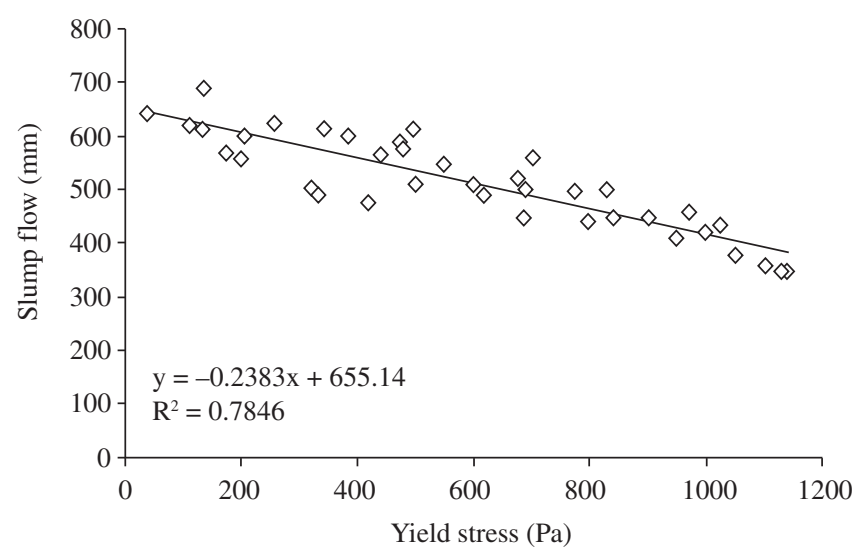

(a)

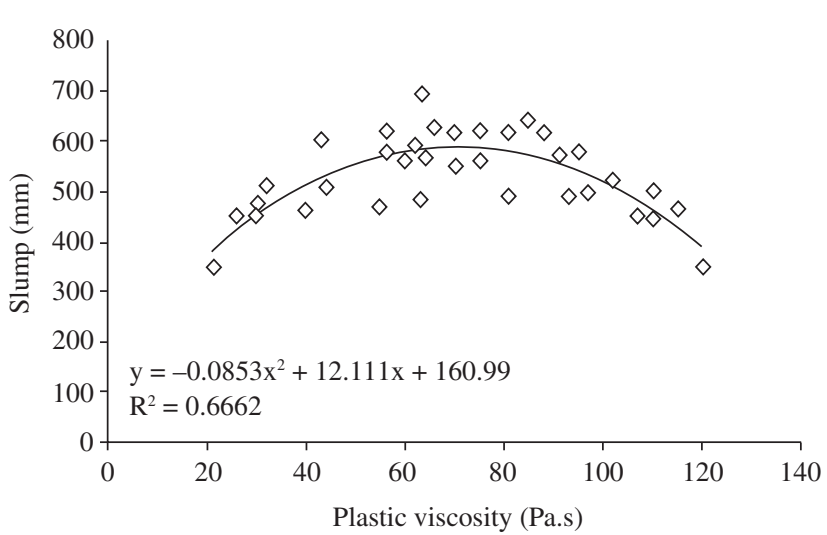

(b)

Figure 4. Relationship between rheological parameters and slump flow a) yield stress and b) plastic viscosity.

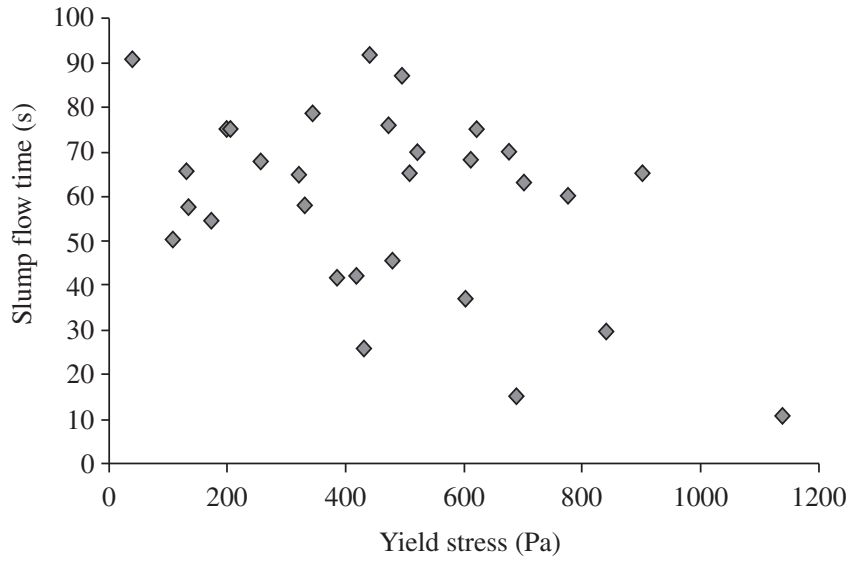

(a)

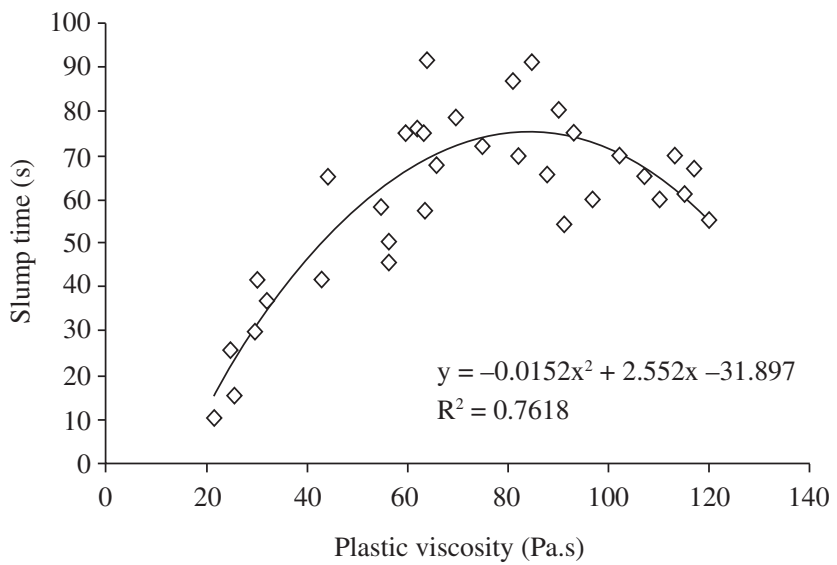

(b)

Figure 5. Relationship between rheological parameters and slump flow time a) yield stress and b) plastic viscosity. 


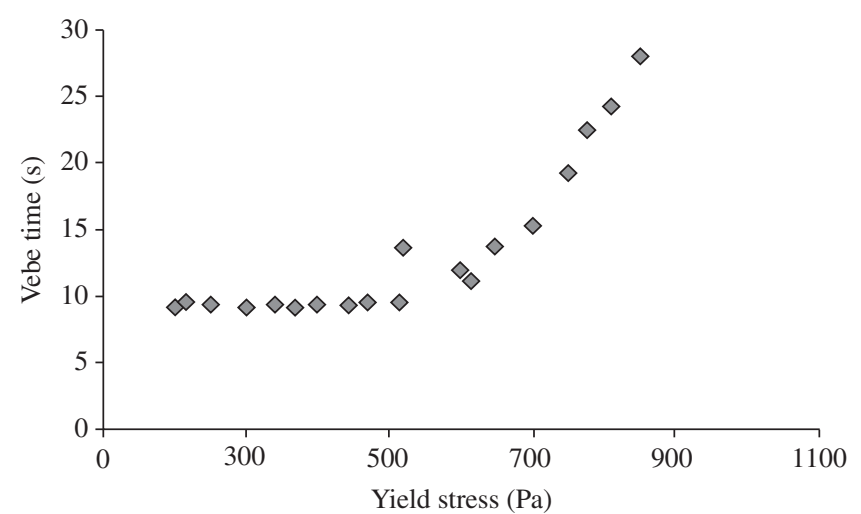

(a)

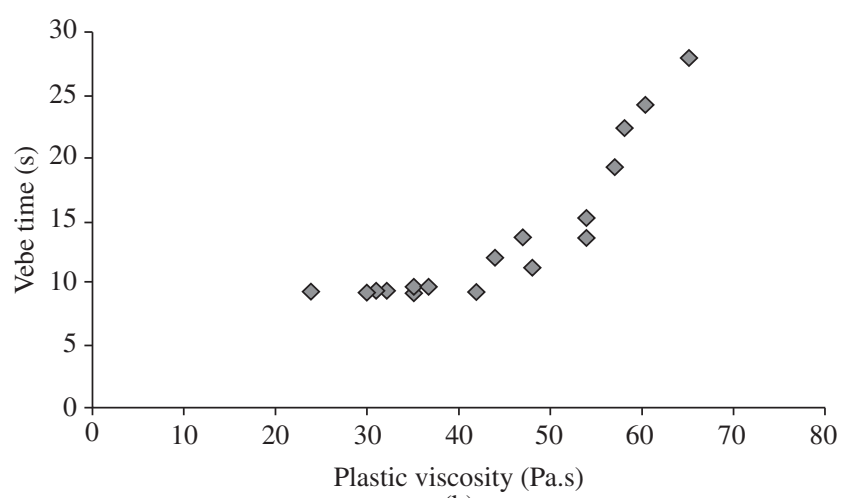

(b)

Figure 6. Variation of rheological parameters with vebe time a) yield stress and b) plastic viscosity.

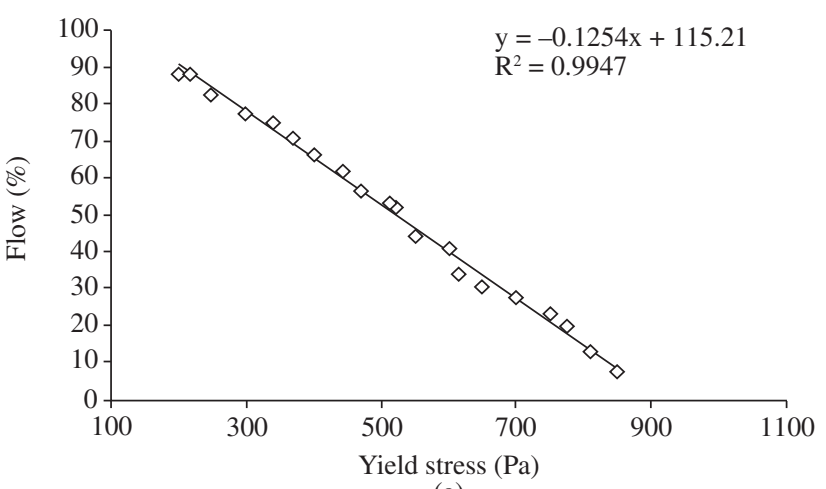

(a)

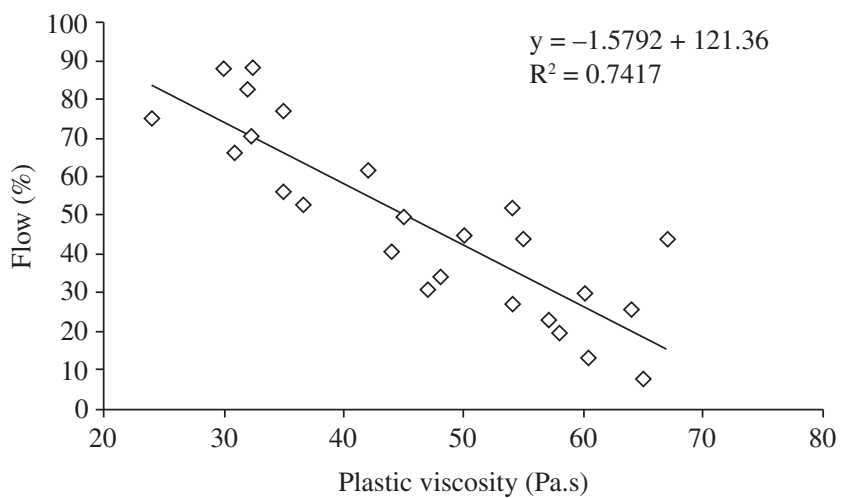

(b)

Figure 7. Variation of percent flow with rheological parameters a) yield stress and b) plastic viscosity.

- No correlation exists between yield stress and slump flow time.

- A relationship also exists between plastic viscosity and slump, plastic viscosity and slump flow, plastic viscosity and slump time. The optimum plastic viscosity is 60-80 Pa.s for maximum slump, maximum slump flow and maximum slump time.

- Vebe time is not sensitive for FRC up to $\tau_{0}=500 \mathrm{~Pa}$ and $\mu=40$ Pa.s beyond which there is a linear increase in Vebe time with the increases in yield stress and plastic viscosity.

- Percent flow decreases linearly with the increase in yield stress of fiber reinforced concrete. Percent flow also decreases linearly with the increase in plastic viscosity.

- Flow test may be a better test for FRC as it is sensitive over all ranges of workability of concrete.

\section{References}

1. Tattersall GH. Workability and quality control of concrete. London: E \& FN Spon; 1991.

2. Tattersall GH, Banfill PFG. The rheology of fresh concrete. Marshfield: Pitman Publishing; 1983.

3. Morinaga J. Pumpability of concrete and pumping pressure in pipelines, Fresh Concrete: important properties and their measurement. In Proceedings of RILEM Conference. [S.L.]: [s.n.]; 1973. p. 7.3.1-7.3.39.

4. Murata J. Flow and definitions of Fresh Concrete. Materials Construction 1984; 17(98):117-129.
5. Christensen G. Modeling of flow properties of fresh concrete: the slump test. [PhD Thesis]. Princeton: Princeton University; 1991.

6. Pashias N, Bogera DV, Summers J, Glenister DJ. A fifty cent rheometer for yield stressmeasurement. Journal of Rheology 1996; 40(6):1179-1189.

7. Tanigawa Y, Mori H. Analytical study of deformation of fresh concrete. Journal of Engineering Mechanics 1989; 115(3):493-508.

8. Tanigawa Y, Mori H, Watanbe K. Computer Simulation of consistency and rheology tests of fresh concrete by viscoplastic finite element method. In Proceeding of RILEM Colloquium: Properties of concrete; 1990. Cambridge, Great Britain: University Press; 1990. p. 301-308.

9. Murata J, Kikukawa H. Viscosity equations for fresh concrete. ACI Materials Journal 1992; 89(3):230-237.

10. Chidiac SE. Correlation of rheological properties to durability and strength of hardened concrete. ASCE Journal of Civil Engineering Materials 2003; 15(4):391-399.

11. Ferraris CF, De Larrard F. Modified slump test to measure rheological parameters of fresh concrete. ASTM-Cement, Concrete and Aggregate 1998; 20(2):241-247.

12. Saak AW, Jennings HM, Shah SP. A generalized approach for the determination of yield stress by slump and slump flow. Cement and Concrete Research 2004; 34(3):363-371.

13. Wallevick JE. Rheology of particle suspension: fresh concrete, mortar and cement paste with various types of Lignosulfonates. [ $\mathrm{PhD}$ Thesis]. Norway: The Norwegian University of Science and Technology; 2003.

14. Johnston CD. Fiber-reinforced cements and concretes. Amsterdam: Gordon and Breach Science Publishers; 2001. 
15. Mehta PK, Monterio PJM. Concrete: microstructure, properties and materials. NJ, USA: McGraw Hill Inc; 2006.

16. Neville AM. Properties of concrete. 2nd Indian reprint. New Delhi: Pearson Education Limited; 2003.

17. IS: $12269-1987$. Indian Standard Code of Practice for 53 grade Ordinary Portland cement. New Delhi: Bureau of Indian Standard; 1987.

18. IS: 2386-1963. Methods of Test for aggregates for concrete. New Delhi: Indian Standard Code of Practice; 1997.
19. JSCE-F503. Method of Test for Slump Flow of Concrete. Tokyo: Standards of Japan Society of Civil Engineers; 1990.

20. IS: 6461 (PT 10)-1973. Glossary of the terms relating to cement concrete: tests and testing apparatus. New Delhi: Indian Standard Institution; 1973.

21. Laskar AI, Talukdar S. Design of a new rheometer for concrete. Journal of ASTM International 2008; 5(1). In press.

22. De Larrard F. Concrete mixture proportioning: a scientific approach. New York: E \& FN Spon; 1999. 